\title{
Standardized Plant Disease Evaluations Will Enhance Resistance Gene Discovery
}

\author{
Joseph Postman ${ }^{1}$ \\ USDA-ARS National Clonal Germplasm Repository, 33447 Peoria Road, Corvallis, OR 97333 \\ Gayle Volk \\ USDA-ARS National Center for Genetic Resources Preservation, 1111 S. Mason Street, Fort Collins, CO 80521
}

\author{
Herb Aldwinckle \\ Department of Plant Pathology, Cornell University, Geneva, NY 14456 \\ Additional index words. Pyrus, Malus, Cydonia, phenotype, database, GRIN, Erwinia, Venturia
}

\begin{abstract}
Gene discovery and marker development using DNA-based tools require plant populations with well-documented phenotypes. If dissimilar phenotype evaluation methods or data scoring techniques are used with different crops, or at different laboratories for the same crops, then data mining for genetic marker correlations is challenging. For example, apples and pears may share many of the same disease resistance genes. Fire blight resistance evaluations for apples often use a scale of 1 to 5 and pear evaluations use a scale of 1 to 9 . In some reports, a low number means low susceptibility and in other reports, a low number means low resistance. Other disease evaluations rate resistance as greater than or less than a welldocumented standard cultivar. Environment, pathogen isolate, and whether disease ratings are the result of natural infection or artificial inoculation also have a strong impact on disease resistance ratings. Before a wider set of disease resistance phenotype data can be correlated with genetic data, rating scales must be standardized and the evaluation environment must be taken into account. Standardizing the recording of disease resistance data in plant phenotype databases will improve the ability to correlate these data with genomic data.
\end{abstract}

Correlation of plant DNA sequence data with disease resistance data, with the goal of discovering genetic markers for valuable genes, is dependent on the existence of plant populations with known disease resistance. Segregating populations generated by crossing a highly disease resistant with a highly susceptible parent often identifies loci containing resistance genes (Pierantoni et al., 2007), but disease evaluations using highly diverse germplasm collections are vital to the discovery of unique resistance genes. The presence of disease resistance information in searchable databases can expedite gene discovery, but publications and databases containing plant disease resistance data are often inconsistent in the scales used to present data.

Plant disease resistance phenotype data can result from three sources: 1) observations of natural disease occurrence in Genebank or breeder collections result in ratings from highly resistant to highly susceptible, often expressed on a numerical scale. Collection plantings may not be replicated or randomized and may consist of a single plant per genotype; 2) intentional replicated inoculations under controlled conditions and evaluation of resulting disease incidence and/or symptom severity. An inoculation study may result in measurements such as canker length, number of lesions per leaf, lesion size, or plant mortality. Controlled studies should include standard cultivars with known disease susceptibility, and disease resistance of various genotypes may be expressed as greater than or less than a standard; and 3) personal anecdotes such as a report of

Received for publication 9 Mar. 2010. Accepted for publication 17 May 2010.

${ }^{1}$ To whom reprint requests should be addressed; e-mail joseph.postman@ars.usda.gov. an apple tree growing for 30 years without developing symptoms of scab or fire blight when many other apple trees were badly affected provide useful information but are difficult to quantify.

Disease resistance data from different studies or reports are often inconsistent in data presentation, so extensive transformations of data are necessary before different data sets can be compared. Some observations of natural disease incidence use a rating of low, medium, or high; others use a scale of 1 to 5 (USDA, 2010a), and still others a scale of 1 to 9 (USDA, 2010b). In some studies, a high rating indicates high resistance and in others, the same rating indicates high susceptibility.

The USDA Germplasm Resources Information Network (GRIN), managed by the Agricultural Research Service, National Plant Germplasm System (NPGS), stores evaluation and characterization data for plant germplasm stored at all NPGS Genebanks in the United States (USDA, 2008). NPGS germplasm data, including taxonomy, origin, phenotype descriptors, and molecular marker information, are stored on the GRIN database. Disease resistance phenotype data gathered from published literature and from evaluations or observations made at NPGS Genebanks are publicly available through online GRIN search utilities (USDA, 2008).

\section{CASE STUDIES FOR APPLE, PEAR, AND QUINCE}

Apple scab. Apple scab caused by Venturia inaequalis (Cke.) Wint. is an important fungal disease worldwide that results in symptoms on both apple leaves and fruit. Fruit with scab symptoms can be unmarketable, except in some niche outlets. In the GRIN database, scab susceptibility of Malus accessions at the NPGS Genebank in Geneva, $\mathrm{NY}$, is rated on a scale from 1 (very resistant) to 5 (very susceptible) with standard cultivars noted for key rating values (Table 1; USDA, 2010a). Hough (1944) used a 5-class scale to rate leaf scab symptoms from 0 (no symptoms) to 4 (typical sporulating lesions). However, symptom variation in apple genotypes ranging from pinpoint pits to stellar lesions, yellow flecks, or necrotic lesions without sporulation necessitated the later addition of intermediate categories (Gessler et al., 2006). King et al. (1998) evaluated a mapping population for scab resistance on 41 occasions using multiple pathogen races, multiple evaluation sites, and different inoculation methods. Symptoms were categorized using a 6 -class scale ranging from 0 to 5 and similar to the Hough scale.

Pear scab. Pear scab caused by the fungus Venturia pirina Aderh. also occurs worldwide and can result in serious loss of crop value wherever pears are grown commercially (Shabi, 1990). Like apple scab, it affects both foliage and fruit. Disease-resistant cultivars require fewer control inputs and can have lower production costs. Pear germplasm at the USDA Genebank in Corvallis, OR, has been evaluated for scab resistance by both controlled inoculations and observation of natural symptoms (Postman et al., 2005). Foliage symptoms were reported as mean number of lesions per leaf, whereas fruit symptoms were rated according to symptom severity per tree over multiple years for the GRIN database descriptor (USDA, 2010b). Unlike the GRIN apple scab rating, which uses a 1 to 5 scale, pear disease descriptors on GRIN use a 1 to 9 scale. A high number on both scales corresponds to high susceptibility.

Pear powdery mildew. Serdani et al. (2005, 2006) evaluated 200 core accessions in the USDA Pyrus germplasm collection for 
Table 1. USDA Germplasm Resources Information Network (GRIN) ratings of susceptibility to apple scab (USDA, 2010a).

\begin{tabular}{lll}
\hline Rating & \multicolumn{1}{c}{ Definition } & Standard cultivars \\
\hline 1 & Very resistant & Liberty \\
2 & Moderately resistant & \\
3 & Intermediate & Golden Delicious \\
4 & Moderately susceptible & Delicious \\
5 & Very susceptible & McIntosh \\
\hline
\end{tabular}

susceptibility to powdery mildew by inoculating potted trees with Podosphaera leucotricha (Ell. \& Ev.) E. S. Salmon. The fungus $P$. leucotricha occurs worldwide and causes the disease powdery mildew on both apples and pears. Powdery mildew on young foliage reduces photosynthetic efficiency, and fruit of susceptible cultivars can develop unsightly lesions that reduce their value (Hickey and Yoder, 1990). Percent of affected pear foliage was determined in the replicated germplasm studies (Serdani et al., 2006), and these data were converted to the standard 1 to 9 pear disease scale used as a GRIN phenotype descriptor (USDA, 2010b). The quince powdery mildew descriptor also uses a 1 to 9 scale (Postman, unpublished data); however, apple powdery mildew resistance is rated on a scale of 1 to 5 (USDA, 2010a). A high rating in all of these crops corresponds to high disease susceptibility.

Fabraea leaf spot. Bell and van der Zwet (1988) used a 1 to 9 scale to characterize Pyrus germplasm for susceptibility to Fabraea fruit and leaf spot caused by Fabraea maculata Atk. [anamorph = Entomosporium mespili (DC.) Sacc.]. In a later replicated field study, the same authors recorded lesion size on a scale of 0 (no lesions) to 4 (large coalescing lesions) in addition to number of lesions per leaf (Bell and van der Zwet, 2005). The NPGS pear and quince germplasm collections are evaluated using a standard 1 to 9 rating scale (USDA, 2010b). Bell and van der Zwet (2005) caution against using only subjective rating scales and suggest evaluating trees for Fabraea leaf symptoms soon after an infection period because partial defoliation may occur in susceptible genotypes, which may skew ratings of the healthier leaves that remain on the tree.

Fire blight. The bacterial disease fire blight, caused by Erwinia amylovora (Burrill) Winslow et al., is one of the most devastating diseases of plants in family rosaceae, and pome fruits such as apple, quince, and pear are especially prone to infection. The most reliable solution to growing these fruits in locations where fire blight occurs is to plant disease-resistant cultivars (van der Zwet and Keil, 1979). Numerous observations, studies, and breeding efforts have been devoted to identifying and developing fire blight-resistant trees and the phenotype data available for this trait have been presented in diverse formats. The NPGS data in GRIN for pears follows the standard 1 to 9 disease rating scale that is used for other pear disease descriptors (USDA, 2010b). This pear fire blight descriptor is based on pear descriptors published by the International Board for Plant
Genetic Resources [IBPGR, later known as the International Plant Genetic Resources Institute (IPGRI), and now BioVersity], which use the 1 to 9 scale with standard cultivars noted for the range of ratings (Table 2; Thibault et al., 1983). The IBPGR apple fire blight descriptor uses the same 1 to 9 scale with $1=$ very resistant and $9=$ very susceptible (Watkins and Smith, 1982) to quantify infection of whole trees. This European scale was designed to correspond to the van der Zwet fire blight scale used by USDA researchers (van der Zwet and Keil, 1979; van der Zwet et al., 1970), although the van der Zwet scale ran in the reverse direction with $10=$ very resistant and $1=$ very susceptible (Table 3). Aldwinckle et al. (1999) and Aldwinckle and Preczewski (1976) followed the convention of many fire blight researchers by reporting lesion lengths as percent of total stem length following artificial inoculation of apple germplasm accessions. Fire blight resistance for apples are stored on GRIN using a 1 to 5 rating scale (Table 4; USDA, 2010a). A cumulative rating of pear and apple cultivars for fire blight resistance was presented by van der Zwet and Keil (1979) in their review of world fire blight literature at the time. They assigned a rating on the van der Zwet scale to each cultivar in each report and compiled several large tables listing a reference as a susceptible report if the van der Zwet rating was between 1 and 5 , as moderately resistant if the rating was 6 to 7 , and as fire blight-resistant if the rating was 8 to 10 . A small excerpt from their pear table is presented in Figure 1. A single cultivar might have many individual reports ranging from susceptible to resistant, but a large number of different reports under one category would provide some consensus that a cultivar was reliably categorized. "Susceptible" reports for a cultivar otherwise widely reported to be field-resistant were often inoculation studies done under ideal disease conditions. A shortcoming of reporting all records equally is that no account is taken of the rigor with which particular studies were conducted, and the definitions of "resistant" and "susceptible" may vary.

\section{STANDARDIZED DISEASE PHENOTYPING}

A standardized scale for recording plant disease resistance data will permit easier comparison between different studies and expedite database queries for correlation with molecular marker data. Therefore, the following standard is proposed:

1. A single digit summary scale should be used for recording disease resistance data. The rating scale should include a maximum number of digits (i.e., 1 to 9) for greater resolution. Whereas a 1 to 5 or low-medium-high scale may be preferred by some researchers or adequate for certain observations, these data can easily be stored in public databases using fewer digits of a standardized 1 to 9 scale. For example, 1-3-5-7-9 can be substituted for $1-2-3-4-5$. Disease data recorded as symptom measurements such as canker lengths or number of lesions should be also be transformed to a standard 1 to 9 rating scale using decimal places if necessary to generate means.

2. A low rating should correspond to low disease incidence (high host resistance) and a high disease rating should correspond to high disease incidence (high host susceptibility).

3. Standard cultivars should be designated for key ratings, especially for the high and low extremes. For example, the GRIN apple scab descriptor designates 'Liberty' with rating $=1$ as the standard for "very resistant" and 'McIntosh' (rating = 5) is the "very susceptible" standard (USDA, 2010a). This will help to transform data sets that do not include samples spanning the entire range of susceptibility.

In addition to the use of a consistent rating scale, factors such as standard inoculation procedures, environmental conditions, age of plants, age of plant tissue and pathogen isolate, and race, if known, are also very important when assessing host resistance. Gessler et al. (2006) reviewed Venturia inaequalis

Table 2. IBPGR pear fire blight descriptor (Thibault et al., 1983).

\begin{tabular}{lll}
\hline Rating & \multicolumn{1}{c}{ Definition } & Standard cultivars \\
\hline 1 & Very resistant & P. ussuriensis \\
2 & Resistant & Old Home \\
3 & Moderately resistant & Kieffer \\
5 & Intermediate & Anjou \\
7 & Susceptible & Bartlett \\
9 & Very susceptible & Aurora, Forelle \\
\hline
\end{tabular}

Table 3. IBPGR apple fire blight descriptor (Watkins and Smith, 1982) and corresponding van der Zwet scale (van der Zwet and Keil, 1979).

\begin{tabular}{lcc}
\hline $\begin{array}{l}\text { IBPGR } \\
\text { rating }\end{array}$ & $\begin{array}{c}\text { van der Zwet } \\
\text { scale }\end{array}$ & $\begin{array}{c}\text { Portion of tree } \\
\text { blighted }\end{array}$ \\
\hline 1 & $10+9$ & $0 \%$ to $3 \%$ \\
2 & 8 & $4 \%$ to $6 \%$ \\
3 & 7 & $7 \%$ to $12 \%$ \\
4 & 6 & $13 \%$ to $25 \%$ \\
5 & 5 & $26 \%$ to $50 \%$ \\
6 & 4 & $51 \%$ to $75 \%$ \\
7 & 3 & $76 \%$ to $88 \%$ \\
8 & 2 & $89 \%$ to $99 \%$ \\
9 & 1 & $100 \%$ \\
\hline
\end{tabular}

Table 4. USDA Germplasm Resources Information Network (GRIN) ratings of apple susceptibility to fire blight (USDA, 2010a).

\begin{tabular}{lll}
\hline Rating & \multicolumn{1}{c}{ Definition } & Standard cultivars \\
\hline 1 & Very resistant & G-41, Robusta \\
& & 5, Novole \\
2 & Moderately resistant & Delicious \\
3 & Intermediate & Empire \\
4 & Moderately & Golden Delicious \\
& susceptible & Jonathan \\
5 & Very susceptible & \\
\hline
\end{tabular}


TABLE 10.-Ratings of pear cultivars for fire blight resistance based on literature cited ${ }^{1}$-Continued

\begin{tabular}{|c|c|c|c|}
\hline Cultivar & $\begin{array}{l}\text { Resistant } \\
(10-8)\end{array}$ & $\begin{array}{l}\text { Moderately } \\
\text { resistant } \\
(7-6)\end{array}$ & $\begin{array}{l}\text { Susceptible } \\
(5-1)\end{array}$ \\
\hline \multicolumn{4}{|c|}{ CULTIVARS ORIGINATED BEFORE 1920-continued } \\
\hline 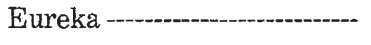 & 389 & 550 & 667 \\
\hline 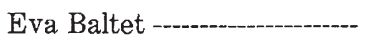 & 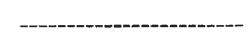 & 389 & $-\cdots$ \\
\hline Fame-- & - & 305,660 & 667 \\
\hline Farmingdale ---_------ & $214,550,626$ & $389,435,780$ & 667 \\
\hline 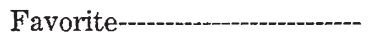 & 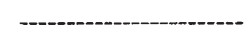 & 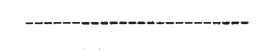 & 22 \\
\hline Figue d'Alencon --------- & 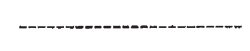 & $389,707,1067$ & 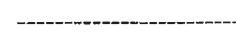 \\
\hline Flemish Beauty---_------- & 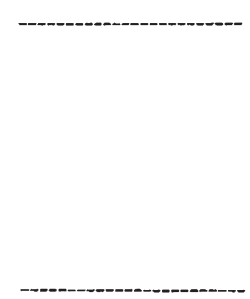 & $159,305,556$ & $\begin{array}{l}20,160,298,317, \\
395,439,486, \\
528,550,587, \\
610,611,667 \\
706,707,769 \\
908,909,923 \\
1011.1108 \\
389.707\end{array}$ \\
\hline $\begin{array}{l}\text { New Zealand Winter } \\
\text { Bartlett. } \\
\text { No Blight-- }\end{array}$ & - & -1-- & 706,707 \\
\hline Notaire Lepin - & - & - & 389,707 \\
\hline Old Home---_- & $\begin{array}{l}67,96,213,214 \\
371,389,439 \\
626,779,780 \\
948,1136\end{array}$ & $\begin{array}{l}317,435,550,706 \\
\quad 707,1067\end{array}$ & 667 \\
\hline Olivier de Serres---_-_----- & - & - & 707 \\
\hline Omer Pache--- & - & - & 389 \\
\hline 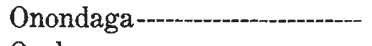 & 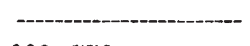 & 305 & 395 \\
\hline Orel - & 389,776 & - & - \\
\hline
\end{tabular}

Fig. 1. Portions of van der Zwet and Keil (1979) summary table itemizing reports in the literature on fire blight susceptibility of individual pear cultivars. Numbers correspond to specific reference citations.

resistance in apple and noted the complexity of genetic mechanisms and symptom expression. Resistance of a particular genotype can be constitutive (quantitative, polygenic, or horizontal resistance) or resistance can be based on a postinfection reaction that is transmitted to progeny in simple Mendelian fashion (qualitative or vertical resistance). King et al. (1998) were able to validate a model that assumed the action of a major apple scab resistance gene segregating in a 1:1 ratio by finding consensus in resistance assessments following a large number of field and glasshouse inoculation studies using the same mapping seedling population. Standardized scales for symptom assessment were used by a number of European laboratories for these studies. Although their data confirmed the usefulness of a number of linkage maps, difficulties were noted in the reliable assessment and classification of individual plants as being resistant or susceptible. Some plants exhibited different symptoms or differed in scab susceptibility at different evaluation locations or in the presence of different pathogen races (King et al., 1998). Evaluation environment details should be included with phenotype results in public databases.

The IBPGR disease phenotype scale of 1 to 9 has been used as a standard at many European Genebanks (Thibault et al., 1983;
Watkins and Smith, 1982) and at some U.S. Genebanks (USDA, 2010b). Universal use of this data standard in germplasm databases will expedite resistance gene discovery by genomic data mining tools. In addition to using standard phenotype data when comparing different data sets, it is also important to know that cultivars with the same name used in different studies are indeed the same. Standardized genotyping markers should be used to verify plant identities in germplasm collections before useful conclusions can be made from the pooling of phenotype data (Evans et al., 2009). When plant phenotype databases standardize the recording of disease resistance data, the ability to search, compare, and correlate data from different sources will become simpler, and new resistance genes will be more easily discovered by correlating these phenotype data with an expanding reservoir of genomic data.

\section{Literature Cited}

Aldwinckle, H.S., H.L. Gustafson, and P.L. Forsline. 1999. Evaluation of the core subset of the USDA apple germplasm collection for resistance to fire blight. Acta Hort. 489:269-272.

Aldwinckle, H.S. and J.L. Preczewski. 1976 Reaction of terminal shoots of apple cultivars to invasion of Erwinia amylovora. Phytopathology 66:1439-1444.
Bell, R.L. and T. van der Zwet. 1988. Susceptibility of Pyrus germplasm to Fabraea leaf spot. Acta Hort. 224:229-236.

Bell, R.L. and T. van der Zwet. 2005. Host resistance in Pyrus to Fabraea leaf spot. HortScience 40:21-23.

Evans, K.M., F. Fernández-Fernández, and C. Govan. 2009. Harmonising fingerprinting protocols to allow comparisons between germplasm collections-Pyrus. Acta Hort. 814:103-106.

Gessler, C., A. Patocchi, S. Sansavini, S. Tartarini, and L. Gianfranceschi. 2006. Venturia inaequalis resistance in apple. Crit. Rev. Plant Sci. 25:473-503.

Hickey, K.D. and K.S. Yoder. 1990. Powdery mildew, p. 9-10. In: Jones, A.L. and H.S Aldwinckle (eds.). Compendium of apple and pear diseases. APS Press, St. Paul, MN.

Hough, L.F. 1944. A suvey of the scab resistance of the foliage on seedling in selected apple progenies. Proc. Amer. Soc. Hort. Sci. 44:260-272.

King, G.J., F.H. Alston, L.M. Brown, E. Chevreau, K.M. Evans, F. Dunemann, J. Janse, F. Laurens, J.R. Lynn, C. Maliepaard, A.G. Manganaris, P. Roche, H. Schmidt, S. Tartarini, J. Verhaegh, and R. Vrielink. 1998. Multiple field and glasshouse assessments increase the reliability of linkage mapping of the Vf source of scab resistance in apple. Theor. Appl. Genet. 96:699-708.

Pierantoni, L., L. Dondini, K.H. Cho, I.S. Shin, F. Gennari, R. Chiodini, S. Tartarini, S.J. Kang, and S. Sansavini. 2007. Pear scab resistance QTLs via a European pear (P. communis) linkage map. Tree Genet. Genomes 3:311-317. 
Postman, J.D., R.A. Spotts, and J. Calabro. 2005. Scab resistance in Pyrus germplasm. Acta Hort. 671:601-608.

Serdani, M., R.A. Spotts, J.M. Calabro, and J.D. Postman. 2005. Powdery mildew resistance in Pyrus germplasm. Acta Hort. 671:609-613.

Serdani, M., R.A. Spotts, J.M. Calabro, J.D. Postman, and A. Qu. 2006. Evaluation of the USDA National Clonal Pyrus Germplasm collection for resistance to Podosphaera leucotricha. HortScience 41:717-720.

Shabi, E. 1990. Pear scab, p. 22-23. In: Jones, A.L. and H.S. Aldwinckle (eds.). Compendium of apple and pear diseases. APS Press, St. Paul, MN.
Thibault, B., R. Watkins, and R.A. Smith. 1983. Descriptor list for pear (Pyrus). IBPGR Secretariat, Rome, Italy. 23 Jan. 2010. <http://www2. bioversityinternational.org/publications/Web_ version/156/>.

USDA. 2008. National Plant Germplasm System, Germplasm Resources Information Network. 17 Jan. 2010. <http://www.ars-grin.gov/npgs>.

USDA. 2010a. USDA ARS GRIN descriptors for apple. 23 Jan. 2010. <http://www.ars-grin.gov/ cgi-bin/npgs/html/desclist.pl?115>.

USDA. 2010b. USDA ARS GRIN descriptors for pear. 23 Jan. 2010. <http://www.ars-grin.gov/ cgi-bin/npgs/html/desclist.pl?88>. van der Zwet, T. and H. Keil. 1979. Fire blight-A bacterial disease of Rosaceous plants. USDA Ag. Handbook 510.

van der Zwet, T., W.A. Oitto, and H.J. Brooks. 1970. Scoring system for rating the severity of fire blight in pear. Plant Disease Reporter 54: 835-839.

Watkins, R. and R.A. Smith. 1982. Descriptor list for apple. International Board for Plant Genetic Resources, Commission of European Communities: Committee on Disease Resistance Breeding and Use of Genebanks. 23 Jan. 2010. <http://www. bioversityinternational.org/fileadmin/bioversity/ publications/pdfs/320.pdf? cache $=1264323695>$. 